\title{
Microperforate Hymen in a Full Term Primigravida in Active Labour
}

\author{
Imtiaz A Shah, M.S., Kamlesh Manhas, M.D., ${ }^{1}$ Nandita Mehta, M.D., ${ }^{2}$ Vipul Gupta, M.B ${ }^{3}$ Manan \\ Shah, M.B. ${ }^{3}$ \\ Department of Urology, 'Gynaecology \& Obstetrics, and ${ }^{2}$ Anaesthesia, and ${ }^{3}$ General Surgery, ASCOMS \& Hospital, Sidhra, Jammu
}

\section{A B S T R A C T}

Micro perforate hymen is a rare congenital entity, mistaken for imperforate hymen. Twenty eight years primigravida from remote rural area with limited medical facilities had to under emergency lower caesarean section for acute labour as no vaginal opening was noticed. Patient was referred to tertiary centre for further management. JMS 2012;15(2):184-85

Key words: Micro perforate, hymen, pregnancy, polydactyly

Hymen is a membrane that surrounds or partially covers the external vaginal opening. It forms part of the vulva or external genitalia. The size of the hymenal opening increases with age. A microperforate hymen is a rare congenital anomaly frequently mistaken for an imperforate hymen having pinhead sized opening, permitting normal menstrual flow which lasts longer due to the fact that blood cannot come out at a normal rate. Pregnancy with intact hymen without emission of penis are very rare entity, and sexual intercourse leads to dyspareunia and disturbances in married life. A minor surgical procedure can be performed to correct the anomaly.

\section{Case report}

28 years female married for last one year, had undergone emergency caesarean section for acute labour, as nurse could not find the vaginal opening at a sub district hospital in a remote area about $150 \mathrm{kms}$ from main district. A live female

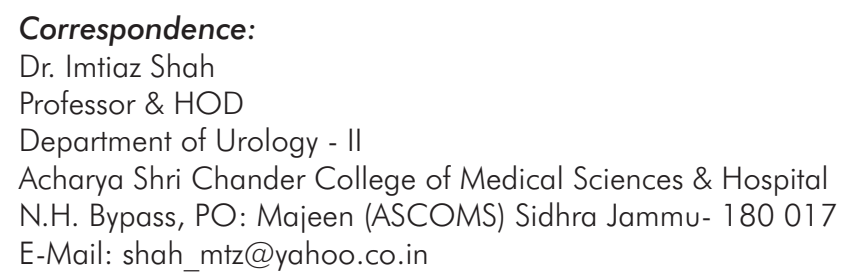

baby was delivered and patient was referred to tertiary hospital for further management on 5th post operative day. Patient was seen in gyne OPD and was referred to urology dept. Patient gave h/o dyspareunia since marriage with nonpenetration of penis during sexual intercourse which had created differences with her husband. Patient gave h/o regular menstrual periods with h/o passing clots on and off during micturition. Patient had no visible congenital defects except bilateral polydactyly. On examination in OPD both labia were normal with normal external urethral opening and no vaginal opening as introitus was covered by tough membrane. On introduction of finger invagination pain in the membrane was noticed. Patient was booked for cystopanendoscopy and examination under anaesthasia. Routine investigations which included CBC, RFT, LFT, U/S abdomen and pelvis were reported normal. Patient was induced with propafol and LMA anaesthesia was given. Cystoscopy with $17 \mathrm{f}$ scope was performed which revealed normal bladder with both uretic orifices were normally placed. On taking the scope out a small dimple was noticed at the posterior lip of external meatus through which scope was introduced with resistance. With Irrigating fluid thick white vaginal membrane bulged out(Figure 1). Vertical incision was given in the middle of membrane which led to normal vaginal opening. Dimple at the posterior part of lower lip of external urethral meatus (Figure 2) through which sperm has traversed to fertilize and through which patient was passing 


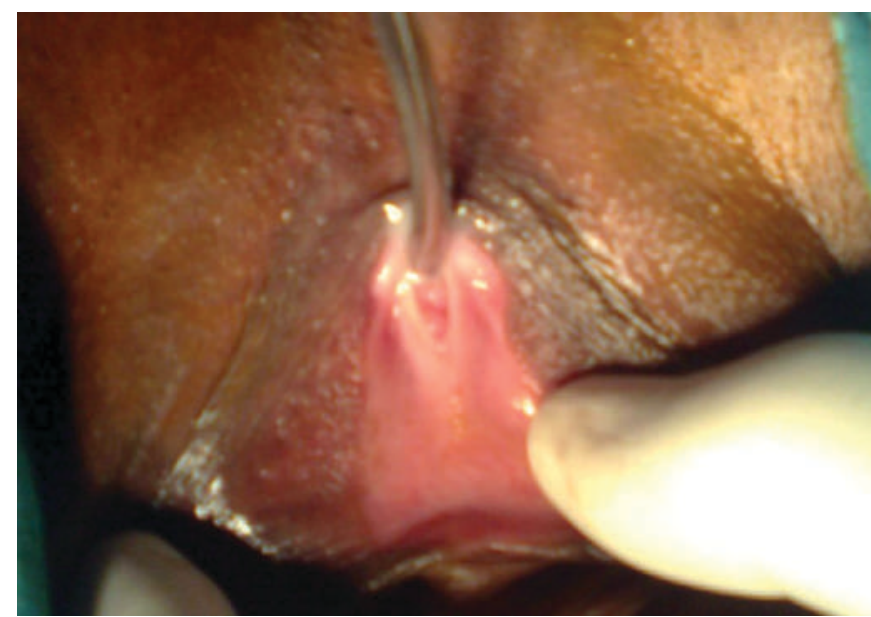

Figure 1

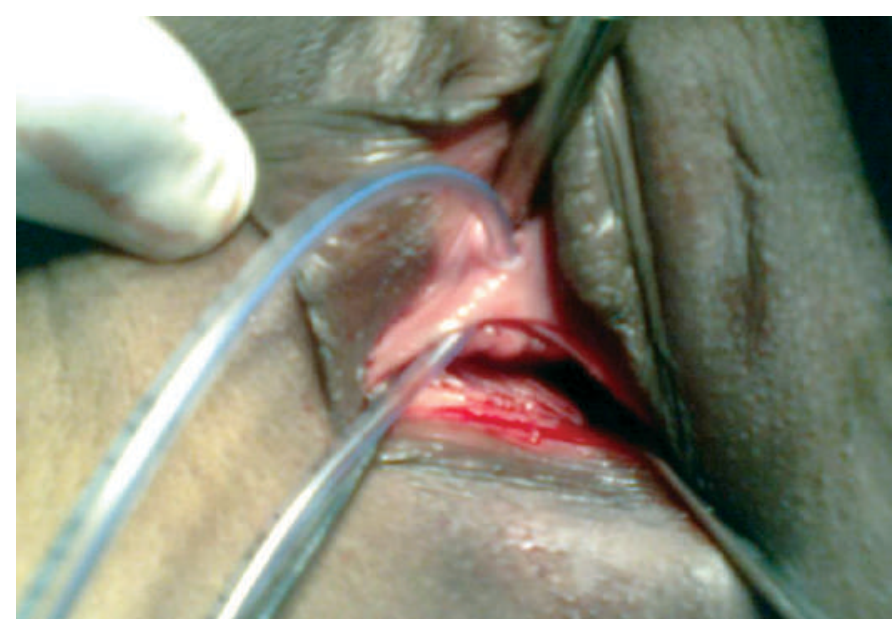

Figure 3

blood during her periods. Free edges of the membrane were stitched to the margins of introits with $3^{\circ}$ vicryl (Figure 3 ). Foleys cather no :14F was put in for few days and patient was discharged on 7 th postoperative day. Patient was followed up after two months enjoying happy married life.

\section{Discussion}

Microperforate hymen is an incomplete obstructive pathology usually permitting normal menstrual flow ${ }^{1,2}$ and pregnancy, as in our case. It may be associated with certain anomalies like bifid clitoris, hypoplastic kidney with ectopic ureter, vascular anomalies, imperforate anus or polydactyly as seen in our case. Illiteracy and ignorance are the reason for late diagnosis as our patient was from a remote area where she had not undergone regular trimestral check-ups. Mostly in such areas nurses perform deliveries as in our case after noticing no vaginal opening she sensibly referred the patient otherwise delay could have led serious problems to both child and mother. Heathcare providers should be aware of this unusual entity especially early in puberty which makes mandatory for clinician to examine the patient in early pregnancy. ${ }^{5}$ Standard surgical treatment of imperforate hymen involves hymenectomy which was performed in our case.

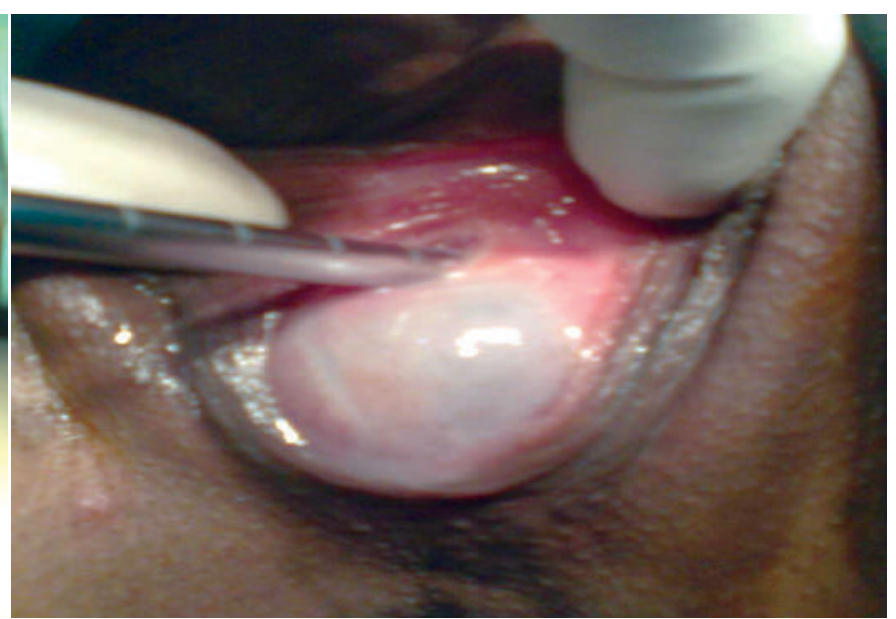

Figure 2

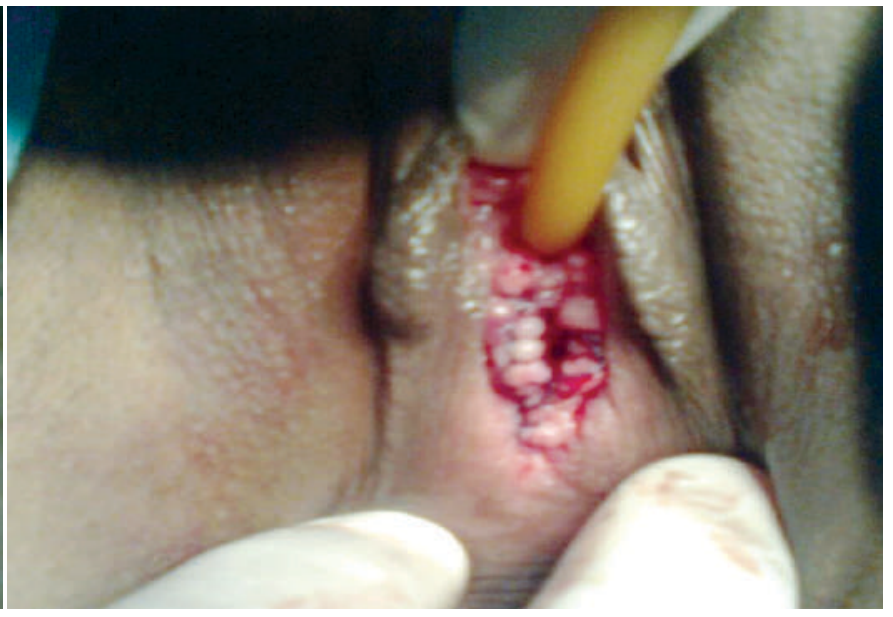

Figure 4

\section{References}

1. Goto K, Yoshinari H, Tajima K, Kotsuji F. Microperofrate hymen in a primigravida in active labor: A case report.J Reprod Med 2006; 51:584-86.

2. Shukunami K, Kaneshima M, Kurokawa T, Kubo M, Kotsuji F. Microperforate hymen at 27 years of age diagnosed with withdrawl bleeding and hysterofiberscopy. Arc Gynecol Obsetet 2000;1:49-50.

3. Wolf B. Pregnancy after ejaculation ante portas in a patient with an anatomical obstruction to intercourse. Zentrabl Gynakol 1988; 110:1457-59.

4. Basaran M, Usal D, Aydemir C. Hymen sparing surgery for imperforate hymen: A case report and review of literature. J Pediatr Adolesc Gynecol 2009; 22:61-64.

5. Acar A, Balci O, Karatayli R, Capar M, Colakogul MC. The treatment of 65 women with imperforate hymen by a central incision and application of Foley catheter. BJOG 2007; 114:1376-79. 